\title{
МЕХАНІЗМ НЕЧІТКОГО ВИВЕДЕННЯ В ІНТЕЛЕКТУАЛЬНІЙ СИСТЕМІ ДІАГНОСТИКИ ЗАХВОРЮВАНЬ
}

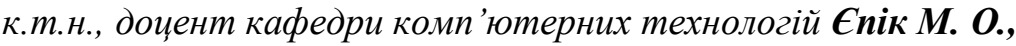 \\ Украӥна, Вінниця, Донецьький національний університет імені Василя Стуса
}

DOI: https://doi.org/10.31435/rsglobal_sr/28022019/6363

\section{ARTICLE INFO}

Received 22 December 2018

Accepted 21 February 2019

Published 28 February 2019

\section{KEYWORDS}

intellectual system, database, base of fuzzy rules, fuzzy mechanism of conclusion, fuzzy system, algorithm Mamdani, fuzzification, defuzzification. \begin{abstract}
This article is devoted consideration of mechanism of fuzzy conclusion in the intellectual system of diagnostics of diseases. The process of realization of inference method is described. The general structure of model of diagnostics of diseases is presented. The example of model fragment is considered. Description of base of fuzzy rules of the intellectual system is presented. The examples of external and internal representation of rules are resulted. The stages of algorithm of fuzzy conclusion of Mamdani are considered. Description of application of algorithm is presented for Mamdani for the intellectual system of diagnostics of diseases.
\end{abstract}

Citation: Спік M. O. (2019) A Mechanism of Fuzzy Conclusion is in Intellectual System of Diagnostics of Disease. Science Review. 2(19). doi: 10.31435/rsglobal_sr/28022019/6363

Copyright: (C) 2019 Спік М. О. This is an open-access article distributed under the terms of the Creative Commons Attribution License (CC BY). The use, distribution or reproduction in other forums is permitted, provided the original author(s) or licensor are credited and that the original publication in this journal is cited, in accordance with accepted academic practice. No use, distribution or reproduction is permitted which does not comply with these terms.

Вступ. Невід'ємною частиною інтелектуальної системи, яка реалізує функції виведення висновків або нових думок на основі інформації з бази знань (БЗ) і бази даних (БД) є механізм логічного виведення. Слід зазначити, що єдиного механізму логічного виведення для інтелектуальних систем (IC) не існує, даний механізм повністю визначається моделлю представлення знань, прийнятою в системі, і існуючі механізми логічного виведення не $\epsilon$ строго фіксованими для кожного типу систем, що засновані на знаннях.

Стратегія керування інтелектуальної системи визначає характер пошуку необхідних знань в Б3 і спосіб організації виведення рішень. Вона є засобом, який використовує міркування або здійснює виводи на основі знань, що містяться в БЗ. Механізм виведення реалізує загальну вбудовану схему пошуку рішень. Стратегії керування забезпечують всіляке керування в межах прийнятої для даної системи схеми механізму виведення.

Процес реалізації стратегії виведення складається з чотирьох етапів: вибір, зіставлення, вирішення конфліктів, виконання. На стадії вибору обираються модулі БЗ і дані з БД, які відносяться до даної ситуації. Відбувається скорочення простору пошуку за рахунок розгляду лише активних модулів і даних, потенційно відповідних до ситуації. На стадії зіставлення на основі порівняння із зразками активних правил і діючих даних визначаються модулі, для яких задовольняються умови виконання. Отримані зазначені модулі складають конфліктну множину оскільки лише деякі з них можуть бути задіяні в поточній ситуації. На стадії вирішення конфліктів приймається рішення, які із зазначених модулів будуть виконуватись в діючому циклі. На цьому етапі застосовуються різні стратегії вирішення конфліктів. На стадії виконання запускаються 
модулі, що обрані на попередній стадії. В результаті виконання модифікуються елементи і структури даних в БД і Б3, видаються необхідні рекомендації або рішення користувачеві.

Результати досліджень. Інтелектуальна система діагностики захворювань $\epsilon$ системою нечіткого виведення, яка заснована на нечітких правилах з лінгвістичними змінними. Система нечіткого виведення - це процес отримання нечітких висновків про необхідне керування об'єктом на основі нечітких умов або передумов, що є інформацією про поточний стан об'єкту.

Розглянемо загальну структуру моделі діагностики захворювань на основі нечітких множин, яка може бути представлена у вигляді сукупності фрагментів:

$$
F=\left\{F_{\sim}^{1}, F_{\sim}^{2}, F_{\sim}^{3}, F_{\sim}^{4}, F_{\sim}^{5}, F_{\sim}^{6}, F_{\sim}^{7}, F_{\sim}^{8}, F_{\sim}^{9}, F_{\sim}^{10}, F_{\sim}^{11}\right\},
$$

де $F^{1}$ - фрагмент, що описує первинні скарги пацієнта,

$F^{2}$ - фрагмент, що описує загальний огляд пацієнта,

$F^{3}$ - фрагмент, що описує систему органів дихання,

$F^{4}$ - фрагмент, що описує систему органів кровообігу,

$F^{5}$ - фрагмент, що описує шлунково-кишковий тракт,

$F^{6}$ - фрагмент, що описує печінку і жовчний міхур,

$F^{7}$ - фрагмент, що описує селезінку і підшлункову залозу,

$F^{8}$ - фрагмент, що описує систему органів сечовиділення,

$F^{9}$ - фрагмент, що описує ендокринну систему,

$F^{10}$ - фрагмент, що описує нервову систему і органи почуттів,

$F^{11}$ - фрагмент, що описує лабораторні і інструментальні методи дослідження.

Сукупність фрагментів (1) на довільний момент часу формується методом фазифікації: переходом від значень вхідних змінних до лінгвістичних змінних і їх функцій приналежності.

Розглянемо як приклад фрагмент моделі діагностики захворювань $F^{3}$, що описує систему органів дихання [4]. Даний фрагмент має вигляд:

$$
F_{\sim}^{1}=\left\{F_{\sim}^{1}, F_{\sim}^{1}, F_{\sim}^{1}, F_{\sim}^{1}, F_{5}^{1}\right\}
$$

де $F_{1}^{1}$ - фрагмент, що описує скарги пацієнта,

$F_{2}^{1}$ - фрагмент, що описує огляд пацієнта,

$F_{3}^{1}$ - фрагмент, що описує пальпацію,

$F_{4}^{1}$ - фрагмент, що описує перкусію легень,

$F_{5}^{1}$ - фрагмент, що описує аускультацію легень.

Фрагмент $F_{1}^{1}$, що описує скарги пацієнта представимий у вигляді:

$$
F_{\sim}^{1}=\left\{\underset{\sim}{F_{11}^{1}}, F_{\sim}^{1}, \underset{\sim}{F_{13}^{1}}, F_{\sim}^{1}, F_{\sim}^{1}, \underset{\sim}{F_{16}^{1}}, \underset{\sim}{F_{17}^{1}}, \underset{\sim}{F_{18}^{1}}, \underset{\sim}{F_{19}^{1}}, \underset{\sim}{F_{110}^{1}}, \underset{\sim}{F_{111}^{1}}, F_{\sim}^{112}, F_{\sim}^{F_{113}^{1}}\right\} .
$$

У (3) перераховані нечіткі характеристики:

$F_{11}^{1}$ - характер кашлю,

$F_{12}^{1}$ - час появи кашлю, 
$F_{13}^{1}$ - тривалість кашлю,

$F_{14}^{1}$ - характер мокротиння,

$F_{15}^{1}$ - кількість мокротиння,

$F_{16}^{1}$ - кількість крові, що виділяється при кровохарканні,

$F_{17}^{1}$ - колір крові при кровохарканні,

$F_{18}^{1}$ - характер болю в грудній клітці,

$F_{19}^{1}-$ інтенсивність болю в грудній клітці,

$F_{110}^{1}$ - характер задишки,

$F_{111}^{1}$ - умови виникнення задишки,

$F_{112}^{1}-$ характер задухи,

$F_{113}^{1}$ - час виникнення задухи.

Розглянемо фрагмент «тривалість кашлю» $-F_{13}^{1}$. Даний фрагмент побудований на знаннях лікарів-експертів і визначений на множині «тижні» [4]: гострий (менше 2 тижнів), затяжний (2-4 тижні), підгострий (4-8 тижнів), хронічний (більше 8 тижнів):

$F_{13}^{1}=\left\{<\right.$ гострий, $\mu_{13.1}^{1}>,<$ затяжний, $\mu_{13.2}^{1}>$, <підггострий, $\mu_{13.3}^{1}>,<$ хронічний, $\left.\mu_{13.4}^{1}>\right\}$.

На Рис.1 представлені графіки функцій приналежності фрагменту «тривалість кашлю»- $F_{13}^{1}$.

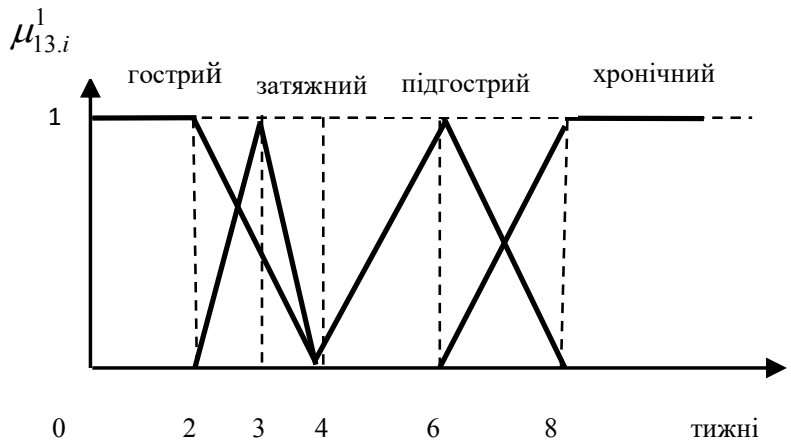

Рис. 1. Графіки функиій приналежності фрагменту $F_{13}^{1}$

База нечітких правил системи організована у вигляді блоків правил у відповідності до пропедевтичного алгоритму системного обстеження хворого лікарем-терапевтом $[3,4]$ : первинні скарги пацієнта, загальний огляд пацієнта, система органів дихання, система органів кровообігу, шлунково-кишковий тракт, печінка і жовчний міхур, селезінка і підшлункова залоза, система органів сечовиділення, ендокринна система, нервова система і органи почуттів, а також блок лабораторних і інструментальних методів дослідження і блок постановки діагнозу.

Оскільки керування для кожної групи правил, що описує обстеження певної системи хворого, передається групі правил постановки діагнозу, то відбувається перетин основних груп правил. Однак це не приводить до суперечності бази правил, оскільки у будь-який момент часу база правил працює тільки з однією з основних груп $[2,3]$. 
База нечітких правил інтелектуальної системи діагностики захворювань $є$ скінчена множина правил нечітких продукцій, погоджених стосовно використовуваних в них лінгвістичних змінних, у формі:

$$
\Pi_{j}: \text { IF нлвв } \text { н }_{j 1} \text { AND нлв }{ }_{j 2} \text { AND } \ldots \text { AND нлв } \text { н }_{j n} \text { THEN нлв }_{j q}\left(v_{j}\right),
$$

де $\left(v_{j}\right)$ - коефіцієнти визначеності відповідних правил: з передумови витікає слідство. Ці коефіцієнти можуть приймати значення 3 інтервалу $[0,1]$. У випадку якщо ці вагові коефіцієнти відсутні, зручно прийняти, що їх значення дорівнюють 1 . нлв $j i-$ нечіткий лінгвістичний вислів.

Нечіткий лінгвістичний вислів нлв $j i$ можна представити у вигляді « $\beta \epsilon \alpha »$, де $\beta$ - назва лінгвістичної змінної, $\alpha$ - iї значення, якому відповідає окремий лінгвістичний терм з базової терм-множини $T$ лінгвістичної змінної $\beta[1]$. Базове правило виведення типу «IF - THEN» (if then rule) називається також нечіткою імплікацією, що приймає форму:

$$
\text { IF « } « € A » \text { THEN «yє } B »,
$$

де $A$ i $B$ - це лінгвістичні значення, ідентифіковані нечітким способом через відповідні функції приналежності для змінних $x$ і $y$. Частина «xє $A »$ називається умовою або передумовою, а «ує $B$ » слідством або висновком. Дану імплікацію можна записати у скороченому вигляді $A \rightarrow B$. Нечітке міркування - це процедура, яка дозволяє визначити висновок, що витікає з множини правил «IF - THEN».

Тоді систему правил нечітких продукцій (5) можна записати у вигляді:

$$
\Pi_{j}: \mathrm{IF} \ll x_{1} \in A_{j 1} » \mathrm{AND} « x_{2} \in A_{j 1} » \mathrm{AND} \ldots \text { AND « } x_{n} \in A_{j 1} » \text { THEN «yє } B_{j} »\left(v_{j}\right),
$$

де $A_{j i}$ - нечітка множина в $X$, яка інтерпретується як умова нечіткого правила продукцій і є сукупністю впорядкованих пар $A_{j i}=\left\{<x_{i}, \mu_{A_{j i}}\left(x_{i}\right)>\right\}$, де $\mu_{A_{j i}}\left(x_{i}\right)-$ функція приналежності і $\mu_{A_{j i}}\left(x_{i}\right): X \rightarrow[0,1]$;

$B_{j}$ - нечітка множина в $Y$, яка інтерпретується як висновок нечіткого правила продукцій і є сукупністю впорядкованих пар $B_{j}=\left\{<y, \mu_{B_{j}}(y)>\right\}$, де $\mu_{B_{j}}(y)-$ функція приналежності і $\mu_{B_{j}}(y): Y \rightarrow[0,1]$; змінні $x_{1}, x_{2}, \ldots, x_{n}$ утворюють $n$-мірний вхідний вектор $x$, що становить аргумент умови.

У нечітких системах існує дві форми представлення правил у базі знань: зовнішня i внутрішня. Зовнішнє представлення передбачає, що правило має бути зрозуміле фахівцеві в предметній області, тобто читабельно. Такий запис правила представлений у вигляді (7). Внутрішнє представлення має бути зрозуміле механізму виведення, який використовує сенс вибраного правила. Для внутрішнього представлення правила використовується наступний запис [2]:

$$
\text { IF } R\left(X_{1}, e\right) \text { AND } R\left(X_{2}, e\right) \text { AND } \ldots \text { AND } R\left(X_{n}, e\right) \text { THEN } R\left(Y_{q}, e\right),
$$

де $R\left(X_{i}, e\right), R\left(Y_{q}, e\right)$ - нечіткі обмеження на значення вхідних і вихідних змінних.

Наведемо приклади зовнішнього представлення правил для визначення типу простудного захворювання [3].

ПРАВИЛО П

IF «Самопочуття_погіршення $\epsilon$ поступове» AND «Температура_тіла $\epsilon$ субфебрильна» AND «Інтоксикація $\epsilon$ не виражена» AND «Нос_нежить_закладеність $\epsilon$ в перші години» AND «Чхання $\epsilon$ присутнє» AND «Горло_біль $\epsilon$ слабка» AND «Очі_дискомфорт $\epsilon$ відсутній» AND «Головна_біль $\epsilon$ відсутня» AND «Підвищена_стомлюваність $\epsilon$ відсутня» AND «Безсоння $\epsilon$ відсутнє»

THEN «Діагноз $\epsilon$ простуда» 
ПРАВИЛО П

IF «Самопочуття_погіршення $\epsilon$ швидке» AND «Температура_тіла $\epsilon$ субфебрильна» AND «Інтоксикація $\epsilon$ часткова» AND «Нос_нежить_закладеність $\epsilon$ в перші дні» AND «Чхання $\epsilon$ присутнє» AND «Горло_біль $\epsilon$ середня» AND «Очі_дискомфорт $\epsilon$ частково присутній» AND «Головна_біль $\epsilon$ часткова» AND «Підвищена_стомлюваність $\epsilon$ часткова» AND «Безсоння $\epsilon$ часткове»

THEN «Діагноз $\epsilon$ гостра респіраторна вірусна інфекція»

ПРАВИЛО П

IF «Самопочуття_погіршення $\epsilon$ раптове» AND «Температура_тіла $\epsilon$ висока лихоманка» AND «Інтоксикація $\epsilon$ сильна» $\overline{A N D}$ «Нос_нежить_закладеність $\epsilon$ через 2-3 доби» AND «Чхання $\epsilon$ відсутнє» AND «Горло_біль $\epsilon$ сильна» AND «Очі_дискомфорт $\epsilon$ присутній» AND «Головна_біль $\epsilon$ сильна» AND «Підвищена_стомлюваність $\epsilon$ часткова» AND «Безсоння $\epsilon$ сильне»

THEN «Діагноз $\epsilon$ грип»

Також наведемо приклад внутрішнього представлення правила для визначення тину простудного захворювання, де $R(x, e)$ - обмеження для лінгвістичної змінної:

\section{ПРАВИЛО П}

IF $R$ (Самопочуття_погіршення, $e$ ) AND $R$ (Температура_тіла, $e$ ) AND $R($ Інтоксикація, $e$ ) AND $R$ (Нос_нежить_закладеність, $e$ ) AND $\quad R$ (Чхання, $e$ ) AND $R$ (Горло_біль, $e$ ) AND $R($ Очі_дискомфорт, $e)$ AND $R($ Головна_біль, $e)$ AND $R$ (Підвищена_стомлюваність, $e$ ) AND $R$ (Безсоння, $e$ )

THEN $R$ (Діагноз, $e$ )

Інформацією, яка поступає на вхід системи нечіткого виведення, є задані певним чином вхідні змінні - скарги пацієнта, результати загального огляду та інші. Інформація, яка формується на виході системи нечіткого виведення, є первинний діагноз пацієнта.

Механізм нечіткого логічного виведення в загальному вигляді включає чотири етапи: фазифікація (введення нечіткості), нечітке виведення, композиція і дефазифікація (приведення до чіткості) $[1,5]$.

Розглянемо реалізацію алгоритму нечуткого виведення Мамдані для даної інтелектуальної системи. Цей алгоритм може бути визначений таким чином: фазифікація вхідних змінних, агрегування підумов, активізація підвисновків, акумуляція висновків, дефазифікація вихідних змінних.

На етапі фазифікації кожному значенню окремої вхідної змінної ставиться у відповідність значення функції приналежності відповідного їй терму вхідної лінгвістичної змінної: $\mu_{A_{j i}}\left(x_{i}\right)$ - функції приналежності для змінної $x_{i}$.

На етапі агрегування підумов використовуються нечіткі логічні операції для знаходження міри істинності умов кожного з нечітких правил. При цьому використовується значення функцій приналежності термів лінгвістичних змінних, що отримані на етапі фазифікації. Якщо умова нечіткого продукційного правила є простим нечітким висловом, то міра його істинності відповідає значенню функції приналежності відповідного терму лінгвістичної змінної. Якщо умова $є$ складений вислів, то міра істинності складеного вислову визначається на основі відомих значень істинності складових його елементарних висловів за допомогою нечітких операцій. Оскільки усі нечіткі правила системи в умовній частині використовують тільки в'язки «AND», то використовуємо логічну min-кон'юнкцію для визначення істинності всього вислову. Правила вважаються активними і використовуються для подальших розрахунків, якщо міра істинності їх умов відмінна від нуля.

На етапі активізації підвисновків правил враховуються лише активні правила для скорочення часу виведення. Поточне значення функції відповідності вихідної змінної (праві частини правил) не може перевищувати істинності передумови (властивість імплікації). Це дозволяє побудувати для кожної з нечітких множин нові множини, відсіканням «верхівок» рівнями істинності. Оскільки висновки робляться відносно вихідних лінгвістичних змінних, то мірам істинності елементарних підвисновків при активізації ставляться у відповідність елементарні функції приналежності. Якщо висновок нечіткого продукційного правила є простим нечітким висловом, то міра його істинності дорівнює алгебраїчному множенню вагового коефіцієнта і міри істинності умови даного нечіткого продукційного правила. Функції приналежності кожного 3 елементарних підвисновків усіх продукційних правил знаходяться за допомогою $\mathrm{min}$-активізації. 
На етапі акумуляції висновків відбувається об’єднання усіх мір істинності підвисновків для отримання функції приналежності кожної 3 вихідних змінних. Процес акумуляції здійснюється по формулі для об'єднання нечітких множин, які відповідають термам підвисновків, що відносяться до одних і тих самих вихідним лінгвістичним змінних.

На етапі дефазифікації відбувається трансформація нечіткої множини у повністю детерміноване точкове рішення у. Для цього використовується один з методів центру тяжіння або центру площі для отримання чіткого значення вихідної лінгвістичної змінної.

Нехай на деякому кроці вибрано правило для обробки ПРАВИЛО П

IF «Самопочуття_погіршення $\epsilon$ поступове» AND «Температура_тіла $\epsilon$ субфебрильна» AND «Інтоксикація $\epsilon$ не виражена» AND «Нос_нежить_закладеність $\epsilon$ в перші години» AND «Чхання $\epsilon$ присутнє» AND «Горло_біль $\epsilon$ слабка» AND «Очі_дискомфорт $\epsilon$ відсутній» AND «Головна_біль $\epsilon$ відсутня» AND «Підвищена_стомлюваність $\epsilon$ відсутня» AND «Безсоння $\epsilon$ відсутнє»

THEN «Діагноз $\epsilon$ простуда»

На етапі фазифікації вхідних лінгвістичних змінних для правила ПРАВИЛО П отримуємо множину значень істинності усіх підумов правила $B=\left\{b_{i}^{\prime}\right\}$, де $b_{i}^{\prime}=\mu_{A_{j i}}\left(x_{i}\right)$ :

«Самопочуття_погіршення $\epsilon$ поступове» $-b_{1}^{\prime}=1$;

«Температура_тіла $\epsilon$ субфебрильна» $-b_{2}^{\prime}=0.76$;

«Інтоксикація $\epsilon$ не виражена»- $b_{3}^{\prime}=0.96$;

«Нос_нежить_закладеність $\epsilon$ в перші години» $-b_{4}^{\prime}=1$;

«Чхання $\epsilon$ присутнє» $-b_{5}^{\prime}=0.83$;

«Горло_біль $\epsilon$ слабка» $-b_{6}^{\prime}=0.88$;

«Очі_дискомфорт $\epsilon$ відсутній» $-b_{7}^{\prime}=0.79$;

«Головна_біль $\epsilon$ відсутня» $-b_{8}^{\prime}=0.96$;

«Підвищена_стомлюваність $\epsilon$ відсутня» $-b_{9}^{\prime}=0.81$;

«Безсоння $\epsilon$ відсутнє» $-b_{10}^{\prime}=0.84$

Множина $B=\left\{b_{i}^{\prime}\right\}$ визначає міру істинності умови нечіткого правила, що складається 3 декількох підумов, при цьому їх лінгвістичні змінні не рівні попарно. Отримуємо множину $B=\left\{b_{i}^{\prime}\right\}=\{1 ; 0.76 ; 0.96 ; 1 ; 0.83 ; 0.88 ; 0.79 ; 0.96 ; 0.81 ; 0.84\}$.

На етапі агрегування використовуємо логічну $\min$-кон'юнкцію для визначення істинності всієї умови, оскільки в даному правилі в умовній частині використовуються лише зв'язки «AND». Тоді отримуємо результат агрегування правила ПРАВИЛО П

$$
b_{1}^{\prime \prime}=\min \{1 ; 0.76 ; 0.96 ; 1 ; 0.83 ; 0.88 ; 0.79 ; 0.96 ; 0.81 ; 0.84\}=0.76 \text {. }
$$

На етапі активізації знаходимо функцію приналежності висновку правила за допомогою алгебраїчного множення вагового коефіцієнта правила, що розглядається, $v_{1}=0.9$ і його міри істинності умови $b_{1}^{\prime \prime}=0.76$. Тоді $c_{1}=v_{1} \cdot b_{1}^{\prime \prime}=0.684$. Таким чином знаходяться усі значення 3 множини $C=\left\{c_{j}\right\}$, де $c_{j}$ - міра істинності підвисновків кожного з правил, що входять в базу нечітких правил системи, $j$ - загальна кількість підвисновків в базі нечітких правил. Після знаходження множини $C$ для вихідних лінгвістичних змінних, що розглядаються, визначаються функції приналежності кожного з підвисновків методом min-активізації:

$$
\mu^{\prime}(y)=\min \left\{c_{j}, \mu_{B_{j}}(y)\right\} .
$$

На етапі акумуляції висновків послідовно розглядаємо кожну з вихідних лінгвістичних змінних $y_{k} \in Y$ і пов'язані 3 нею нечіткі множини: $C_{k 1}, C_{k 2}, \ldots, C_{k j}$. Далі проводимо об'єднання усіх мір істинності підвисновків для отримання функції приналежності кожної 3 вихідних змінних методом тах-об'єднання:

$$
C_{1}^{\prime}=\max \left\{C_{1 j}\right\}
$$


де $j$ - загальна кількість підвисновків в базі нечітких правил.

На етапі дефазифікації знаходимо чітке значення вихідної лінгвістичної змінної за допомогою методу центру тяжіння для одноточкових множин:

$$
y^{*}=\frac{\sum_{i=1}^{L} y_{i} \cdot \mu\left(y_{i}\right)}{\sum_{i=1}^{L} \mu\left(y_{i}\right)},
$$

де $y^{*}$ - результат дефазифікації; $y_{i}-$ вихідні лінгвістичні змінні; $\mu\left(y_{i}\right)$ - функції приналежності нечітких множин вихідних змінних після етапу акумуляції. Підсумовування здійснюється за усіма $L$ правилам.

Висновки. Знання про предметну область, для якої створюється інтелектуальна система, не $є$ повними і абсолютно достовірними. Навіть кількісні дані, отримані шляхом точних вимірів і експериментів, мають статистичні оцінки достовірності. Більшість знань, використовуваних в інтелектуальній системі діагностики захворювань, отримані у результаті опиту лікарів-експертів, думки яких суб'єктивні і часто розходяться. Тому вживання жорстких механізмів формальної логіки при обробці таких знань викликає протиріччя між нечіткими знаннями і чіткими методами логічного виведення. Вирішити це протиріччя можна використанням механізму нечіткого логічного виведення, опис якого представлений в даній статті.

\section{ЛІТЕРАТУРА}

1. Леоненков А. В. Нечітке моделювання у середовищі MATLAB i fuzzyTECH/ А. В. Леоненков. СПб: БХВ-Петербург, 2003: 736.

2. Каргін А. О. Введення в інтелектуальні машини. Книга 1. Інтелектуальні регулятори/ А. О. Каргін. Донецьк: Норд-Пресс, ДонНУ, 2010: 526.

3. ЄПік М. О. МОДЕЛЬ ПРЕДСТАВЛЕННЯ ЕКСПЕРТНИХ ЗНАНЬ В ІНТЕЛЕКТУАЛЬНІЙ СИСТЕМІ ДІАГНОСТИКИ ЗАХВОРЮВАНЬ / М. О. ЄПік. - INTERNATIONAL ACADEMY JOURNAL Web of Scholar ISSN 2518-167X 1(31), Vol.1, January 2019 - Warsaw, Poland: RS Global Sp. z O.O., 2019: pp. 3-7.

4. Івашкін В. Т. Пропедевтика внутрішніх хвороб: підручник для студентів медичних вузів/ В. Т. Івашкін, А. А. Шептулін. - М.: МЕДпресс-інформ, 2005: 229.

5. Tagaki T. Fuzzy identification of systems and its applications to modeling and control/ T. Tagaki, M. Sugeno. - IEEE Transactions of Systems, Man, and Cybernetics, vol. 15, no 1, 1985: 116-132. 